\title{
RELAÇÃO HOMEM-ANIMAL E BEM-ESTAR DO CÃO DOMICILIADO
}

\author{
Sheila Andrade Ferreira ${ }^{1}$, Ivan Barbosa Machado Sampaio ${ }^{2}$ \\ ${ }^{1}$ Escola de Veterinária da Universidade Federal de Minas Gerais - neshivile@yahoo.com.br
}

\begin{abstract}
RESUMO: O objetivo principal deste estudo foi verificar alguns aspectos da associação entre a relação homem-animal e o bem-estar do cão. Foram estabelecidas as relações funcionais entre as condições de criação de 60 cães, a progressividade e a atitude de seus proprietários e o bem-estar animal, por meio de análise multivariada de correspondência múltipla. O modelo de investigação utilizado na pesquisa foi do tipo exploratório de caráter descritivo com pesquisa de campo. Realizouse um inquérito e observações das condições de criação de cães domiciliados. A seleção das residências foi realizada de modo fortuito e sistemático, visando obter variabilidade do tipo de residência e diversidade socioeconômica dos participantes. A índole, o estado de tranquilidade e a avaliação corporal foram os três indicadores utilizados para a medição do bem-estar animal. O cão simultaneamente manso, tranquilo e com condição corporal ideal foi considerado desfrutar do bemestar adequado. Apenas $43,3 \%$ da população canina experimentava bem-estar adequado por ocasião da entrevista. Dentre os três indicadores utilizados, condição corporal e estado de tranquilidade mostraram-se ser indicadores mais apropriados para medir o bem-estar pobre que 0 bem-estar adequado. Concluiu-se que a progressividade, a atitude positiva e o comprometimento do proprietário com os cuidados necessários para proporcionar uma boa qualidade de vida ao cão, não foram suficientes para favorecer o bem-estar adequado de $56,6 \%$ da população estudada.
\end{abstract}

Palavras-chave: bem-estar animal; cão; vínculo homem-animal

\section{HUMAN-ANIMAL RELATIONSHIP AND WELFARE OF THE DOMICILED DOG}

ABSTRACT: The aim of this study was to verify the eventual association between man-dog relationship and the animal welfare. Relationships among raising conditions of 60 dogs, owner's progressiveness and attitude and animal welfare were studied through multiple correspondence analysis. The investigation model used in the research was of the exploratory type of descriptive character with field research. Data were collected at households through an inquiry. Residences were selected according to a systematic sampling procedure covering type of residence and socioeconomical levels. Behavior, peacefulness state and body state evaluations were the three indicators used for measuring animal welfare. Dogs simultaneously tame, peaceful and with ideal body condition were considered to experience appropriate welfare. Only $43.3 \%$ of the canine population could be classified as under appropriate welfare during interviews. Among the three used indicators, corporal condition and state of peacefulness were shown to best characterize poor welfare rather than appropriate welfare. Results suggested that progressiveness, positive attitude and the owner's attention and care to provide a good life quality to his dog, did not imply in its adequate welfare, in $56.6 \%$ of studied population.

Key words: animal welfare; attachment; dog; pet-human bond 


\section{INTRODUÇÃO}

Muitos cães em razão da convivência com 0 ser humano experimentam situações que o incitam à frustração, ao medo, à agressão e à ansiedade. Estas emoções podem comprometer o seu bem-estar e colocar em risco o bem-estar da família que o acolhe. Provavelmente, os cães que sofrem instabilidade emocional por conviverem com uma família humana, ainda não estão programados geneticamente para viver sob alta pressão, onde a frequência e a intensidade de situações especiais que o induzem às reações de ordem física e psíquicas, excedem o nível considerado normal para a sua espécie.

Os fenômenos físicos e psicológicos, a vida social e o ambiente, são interativos. (Kandel et al., 1997). Qualquer mudança no meio externo (ambiente físico ou psicossocial), ou interno (somáticos ou psicológicos), pode provocar no animal uma resposta fisiológica ou comportamental. Os estímulos podem ser agradáveis ou aversivos e as respostas do animal para estes estímulos determinam 0 seu estado de bem-estar. Geralmente, as respostas funcionam como um mecanismo protetor para devolver ao animal o estado de equilíbrio. Se as respostas não são eficazes para facilitar a manutenção ou retomada da homeostase, o animal pode desenvolver um processo de deficiência orgânica, inaptidão, desordem comportamental ou doença (Clark et al., 1997a).

Sendo o bem-estar de um indivíduo o seu estado em relação as suas tentativas de adaptar-se ao seu ambiente (Broom, 1986), a avaliação de bem-estar, mede as tentativas de adaptação do animal em uma escala que varia de adequado a pobre. A caracterização de bem-estar adequado significaria que 0 animal não tem nenhum problema para resolver alcançando facilmente à adaptação. O bem-estar pobre expressaria o empenho do animal em enfrentar a condições adversas através de extremas respostas fisiológicas ou comportamentais.

O processo de adaptação ao envolver respostas de comportamento e fisiológicas, permite ao animal controlar e manter a estabilidade mental e corporal. Este processo inclui regulação do estado normal do corpo acompanhado de respostas de emergência, como atividade adrenal alta, taxa de coração ou outras atividades que podem requerer mais gastos de energia. Esse gasto de energia, no entanto depende da predição do animal, da sua percepção sobre a adequabilidade das ações reguladoras normais (Broom, 1991). O seu bem-estar dependerá do sucesso em adaptar-se às condições proporcionadas pelo ambiente físico e psicossocial onde vive. Em algumas situações a adaptação é difícil e o animal consegue adaptar-se com grande dificuldade, em outras, apesar de todo o seu esforço, não alcança a adaptação, sobrecarregando o sistema de controle.

Em uma avaliação de bem-estar é importante considerar as emoções dos animais e a variação individual nas tentativas de adaptação às adversidades e aos efeitos que essa adversidade causa ao animal. Sendo as respostas fisiológicas e comportamentais diferentes para diferentes indivíduos e para diferentes problemas, é necessário incluir em um estudo de bem-estar vários indicadores para a realização de distintas medidas. Se o animal utiliza diversos métodos para tentar se adaptar aos diferentes efeitos adversos, o uso de apenas um indicador para avaliar a sua reação poderia indicar que ele está adaptado ao ambiente (Broom e Fraser, 2007). O 
emprego simultâneo de indicadores fisiológicos e comportamentais validaria os métodos de avaliação de adaptação do animal e a caracterização do bemestar seria mais precisa.

O comportamento utilizado como indicador apresenta um valor peculiar na avaliação do bem-estar. Apesar de ele medir a tentativa do animal em adaptarse às adversidades como os demais indicadores, o pesquisador ao estimar 0 comportamento de ansiedade, agressividade ou inatividade, obtém importante informação a respeito dos sentimentos do animal e sobre seu bem-estar (Broom, 1998). Há três décadas Duncan (1981) assinalou que o comportamento transtornado pode indicar mais sutilmente e mais depressa quando o bem-estar de um animal é adversamente afetado.

Considerando que os fatores determinantes do bem-estar ainda são pobremente compreendidos e métodos de avaliação do bem-estar do cão, todavia não foram validados, este estudo, com o objetivo principal de verificar alguns aspectos da relação homem-animal associados ao bem-estar do cão, torna patente o desafio de se desenvolver uma pesquisa acadêmica envolvendo a relação homem-animal e o bem-estar do cão. Para alcançar o objetivo delineado buscou-se conceitos desenvolvidos por estudiosos da área, aplicou-se novos instrumentos métodológicos e estabeleceu-se indicadores para a medição do bem-estar.

A relevância prática deste estudo se constitui em fixar a base intelectual e científica para crescimento futuro dessas áreas e prover informação clínica prática para profissionais e estudantes que lidam com animais. Aprimorar a habilidade para identificar e medir sofrimento dos cães tem valor óbvio para os animais e para a sociedade.

\section{MATERIAL E MÉTODOS}

O modelo de investigação utilizado na pesquisa foi do tipo exploratório de caráter descritivo com pesquisa de campo. A investigação constou de observações e um inquérito das condições de criação de cães domiciliados.

A abordagem quantitativa caracterizada pela quantificação da informação e o tratamento estatístico e matemático dos dados, foi utilizada para identificar as opiniões e atitudes dos proprietários dos cães, testar a fiabilidade do questionário, estabelecer a frequência das condições de criação e estimar a condição corporal dos animais. A abordagem qualitativa, por outro lado, consistiu na observação e na descrição do comportamento de variáveis relativas a elementos que poderiam estar influenciando o bem-estar animal.

A hipótese do estudo foi de que as atitudes e a progressividade dos proprietários e as condições de criação seriam fatores determinantes para a promoção do bem- estar animal. A pesquisa desenvolvida na Região Administrativa da Pampulha da cidade de Belo Horizonte, MG, Brasil, teve como amostra 60 residências onde era criado apenas um cão com idade igual ou superior a doze meses. O proprietário foi caracterizado como um indivíduo da família com idade superior a 18 anos, mais envolvido no dia-a-dia do animal e comprometido com o seu cuidado.

Os instrumentos de coleta de dados constaram de três formulários, observação direta e um questionário para avaliação das atitudes e progressividade dos proprietários em relação ao bem-estar animal. Os três formulários foram elaborados para coletar: 1) dados sobre o cão e dados sócio-econômicos (classe de renda e tipo de residência); 2) caracterização do 
sistema de criação e 3) avaliação física e comportamental do animal.

A escolha das variáveis empregadas na caracterização da qualidade dos sistemas de criação dos cães fundamentou-se nas 'cinco liberdades', estabelecidas em 1993 pelo Comitê de Bem-Estar Animal de Produção, para a avaliação do bem-estar animal (Bekoff, 1998). Pretendeu-se avaliar a observância dos proprietários às necessidades fisiológicas, comportamentais e psicológicas do cão. Os dados relativos ao sistema de criação foram: espaço disponível (satisfatório/ insatisfatório); condição de liberdade do animal (livre/acorrentado); acesso às dependências internas da residência (sim/não); local onde dorme (nas dependências internas da residência /fora); domiciliação (mantido na residência/ acesso livre ao logradouro público); higienização do local onde dorme, urina e defeca (satisfatório/ insatisfatório); imunização contra raiva e outras doenças infecciosas (sim/ não); vermifugação (sim/não); controle dos parasitos externos (sim/não); tratamento respeitoso (sim/não); brincadeira e exercício diários (satisfatório/insatisfatório) e passeios (satisfatório/ insatisfatório).

No terceiro formulário, as variáveis 'condição corporal', 'índole' e 'estado de tranquilidade' empregadas como indicadores na avaliação do bem-estar animal, serviram para considerar 0 efeito de fatores biopsicossociais resultante de estímulos e respostas que influenciam a condição corporal do animal (Hofer e East, 1998) e o comportamento (Clark et al., 1997b).

A associação de alguns aspectos da relação homem-animal com o bemestar do cão foi demonstrada por meio da análise multivariada de correspondência múltipla. As variáveis referentes à relação homem-animal foram: 1) aspectos da diversidade socioeconômicas dos proprietários 2) condições de criação do cão e (3) progressividade e a atitude dos proprietários. As variáveis referentes ao bem-estar foram: 'condição corporal', 'índole' e 'estado de tranquilidade', 'bem-estar adequado' e 'bem-estar pobre'.

A observação do comportamento do animal, das condições de criação e da interação do proprietário com o seu animal foi iniciada exatamente no momento em que o proprietário abriu a sua porta para receber a pesquisadora. Através de uma atitude profissional, mas amigável, a pesquisadora deixou o respondente à vontade e ao mesmo tempo, com um ar de informalidade, observava as respostas do proprietário ao comportamento do animal, enquanto incluindo sua atividade, nível de excitabilidade, exploração, respostas de medo e agressividade, e interação com pessoas estranhas (a própria entrevistadora) e familiares. Foi indagado aos proprietários se eles identificavam em seus cães os comportamentos de agressividade e de intranquilidade. Em seguida, foram perguntados pormenores sobre 0 comportamento do cão e de seus pais, convergindo para um mesmo ponto dos possíveis problemas. Quando 0 proprietário não admitia dúvida, ainda assim, era solicitada informação mais objetiva, e perguntas específicas eram feitas sobre as manifestações observadas e a frequência de ocorrência de agressividade e intranquilidade. Quando era notória a incerteza, e o proprietário por motivos não ditados pela razão se abstinha em considerar a verdadeira natureza do problema, o entrevistador baseado nos fatos, na sua experiência e no juízo crítico, decidia como árbitro.

O questionário foi utilizado para avaliação das atitudes e progressividade dos proprietários em relação ao bem-estar animal. Progressividade, segundo Guilhermino e Sampaio (1999), 
se refere à conquista de conhecimentos objetivos capazes de modificar a vida íntima e social e de conceder maior significação no contexto da experiência humana. Os indivíduos progressistas, ao contrário dos conservados na tradição, são mais abertos à mudança e atuam como fontes de informação para outros indivíduos não-progressistas.

Utilizou-se o Método de Avaliações Somadas de Likert (Zimbardo e Ebbersen, 1973) para a colheita de dados. Vinte e quatro perguntas fechadas (Anexo) foram elaboradas para investigar os elementos cognitivos das atitudes e progressividade dos proprietários para com o bem-estar de seus cães. As perguntas sob forma afirmativa ou negativa estavam divididas em quatro grupos: atitudes positivas, atitudes negativas, proprietário tradicional e proprietário progressista. As respostas foram fixadas em uma escala de sete pontos que registrou a concordância ou discordância do respondente com cada item ou pergunta feita pelo entrevistador: (7) concordo totalmente (6) concordo parcialmente (5) concordo um pouco (4) não sei (3) discordo um pouco (2) discordo parcialmente (1) discordo totalmente. Se o respondente não tivesse bastante conhecimento para formar uma opinião sobre uma afirmação em particular, ele tinha a opção de escolher "não sei". Cada resposta representada na escala de 01 a 07 é uma função linear da mesma dimensão de atitude/ progressividade. Logo, o resultado ou quantificação da atitude/progressividade do entrevistado é a adição das avaliações isoladas.

$\mathrm{Na}$ determinação da Condição Corporal Canina foram empregados dois métodos para determinar se o cão estava acima ou abaixo do peso normal: (1) Índice de condição corporal - método de avaliação da condição corporal baseado na inspeção e palpação do animal (Laflamme, 1997) e (2) Índice de massa corporal canino (IMCC) - método simples e objetivo de quantificação da massa corporal (Müller, 2007). O primeiro método de cunho subjetivo foi utilizado neste estudo com o intuito de validar o IMCC.

Com o propósito de atender as diversas circunstâncias relativas à individualidade do animal, foram empregadas conjuntamente variáveis de caráter físico e comportamental como indicadores na avaliação do bem-estar. Os três indicadores eleitos fundamentaram-se em respostas interna e comportamental do cão (Clark et al., 1997b). A resposta interna foi representada pelo indicador 'condição corporal' e as respostas comportamentais pelos indicadores 'índole' e 'estado de tranquilidade'. A partir destas três variáveis foram criadas seis classes de variáveis: 'condição corporal ideal' / 'condição corporal inapropriada'; 'agressivo' / 'manso'; 'tranquilo' / 'intraquilo'.

Para a determinação da índole agressiva não foi levado em consideração o tipo de agressividade, pois o que determina a índole ou o comportamento de um cão não depende exclusivamente da raça, se ela é agressiva ou mansa, mas também, e principalmente, do modo como esse cão foi criado e treinado (Jagoe e Serpell, 1996). Independente da causa que levou o cão a apresentar uma agressividade despropositada, os proprietários serão sempre os responsáveis pelos atos de seus animais e não o contrário. O estado de intranquilidade, caracterizado por ansiedade, excitabilidade e constante atividade, é considerado um comportamento anormal, um sinal de alarme, enquanto revelando um desequilíbrio entre o animal e seu ambiente. Geralmente, este estado está associado ao não atendimento de alguma necessidade do animal, seja ela de interação, atividade física ou exploração de ambientes. 
O bem-estar foi caracterizado como adequado quando, simultâneamente, o animal apresentava a 'condição corporal', a 'índole' e o 'estado de tranquilidade' satisfatórios. De outro modo, o cão possuidor de bem-estar adequado seria um animal com 'condição corporal ideal', 'manso' e 'tranqüilo'. Para caracterização do bemestar pobre bastava que o animal apresentasse 'condição corporal inapropriada' e/ou fosse 'agressivo' e/ou fosse 'intranquilo'.

Foi considerado neste estudo que o bem-estar do cão depende, entre muitos fatores, de uma relação homemanimal satisfatória. Um animal que experimenta bem-estar provavelmente vive em um ambiente onde as pessoas lhe proporcionam saúde física e mental. Deste modo, os resultados obtidos com a caracterização do sistema de criação (satisfatório/insatisfatório), com a caracterização das atitudes (positivas/ negativas) e progressividade (progressista/tradicional) dos proprietários e avaliação do bem-estar (adequado/ pobre) foram aplicado na caracterização da relação homem-animal (satisfatória/ insatisfatória).

O primeiro passo da análise dos dados foi conhecer as frequências de respostas para as variáveis socioeconômicas e de outras variáveis utilizadas na caracterização da qualidade do sistema de criação e do bem-estar do animal. O segundo foi verificar os índices de atitude e progressividade dos proprietários. No terceiro passo procedeu-se a análise multivariada de correspondência múltipla para identificar as associações existentes entre as variáveis pesquisadas e o bem-estar animal. Por último, caracterizou-se a relação homemanimal levando em consideração os resultados obtidos dos quatro passos anteriores.

Perante as circunstâncias da conjuntura analítica desta pesquisa, a análise dos dados baseou-se principalmente na análise estatística descritiva e na análise multivariada de correspondência múltipla, não obstante, essas análises ao caracterizarem 0 perfil da amostra e demonstrarem associações entre variáveis, respectivamente, convergiram para a caracterização do bem-estar animal e da relação homem-animal na população estudada.

A resposta referente a cada um dos 24 questões do questionário foi quantificada segundo a escala de Likert de 01 a 07 . Os índices que caracterizaram cada proprietário dentro das duas variáveis progressividade $\left(P_{k}\right)$ e Atitudes $\left(A_{k}\right)$ em relação ao bem-estar animal foram calculados usando a seguinte fórmula matemática (Guilhermino e Sampaio, 1999):

$$
P_{k \text { ou }} A_{k}=\left(n_{2} \sum_{i=1}^{n_{1}} X_{i}-n_{1} \sum_{j=1}^{n_{2}} X_{j}\right) / n_{1} n_{2}
$$

$P_{k}$ - Progressivo $x$ Tradicional $\left(A_{k}\right.$ - Atitude positiva $x$ atitude negativa)

$\mathrm{X}_{\mathrm{i}}$ - valor do item progressividade (ou atitudes positivas)

$X_{\mathrm{j}}$ - valor do item tradicional (ou atitudes negativas) $\mathrm{n}_{1}$ - número de itens / produtores progressistas (ou atitudes positivas)

$\mathrm{n}_{2}$ - número de itens / produtores tradicionalistas (ou atitudes negativas)

Onde $\mathrm{P}_{\mathrm{k}}$ é o índice para o $\mathrm{k}$ produtores, os quais responderam afirmativamente para $n_{1}$ itens (questões) de progressividade $\left(\mathrm{X}_{\mathrm{i}}\right)$ e $\mathrm{n}_{2}$ itens tradicional $\left(\mathrm{X}_{\mathrm{j}}\right)$.

Os dois índices $P_{k}$ e $A_{k}$ para cada um dos respondentes foram representados graficamente em dois eixos, definindo os quatro quadrantes. 0 gráfico de dispersão foi obtido com o auxílio do Assistente de gráfico do Microssoft Office Excel versão 2003.

Foi medida a fiabilidade do questionário para atestar a consistência ou a estabilidade das medidas obtidas pelo instrumento utilizado na colheita de dados. Para atender este preceito metodológico, o questionário foi ministrado duas vezes. $\mathrm{Na}$ primeira vez, presencialmente na residência do 
proprietário, e na segunda vez através de contato telefônico. O Coeficiente de Correlação de Spearman obtido foi de 0,93 .

O emprego da análise multivariada de correspondência múltipla é usualmente indicado, quando se quer realizar uma analise simultânea de um número expressivo de variáveis qualitativas para descobrir possíveis relações existentes entre elas. Esta análise multidimensional permite também conhecer prováveis agrupamentos e quais fatores predisponentes estão mais associados à variável principal. As possíveis relações existentes entre as variáveis são verificadas por meio de uma abordagem descritiva baseada em observações gráficas que permitem examinar 0 comportamento de cada variável em relação às demais. $\mathrm{O}$ programa computacional empregado para a análise multivariada de correspondência múltipla foi o InfoStat da Universidade de Córdoba, Argentina.

\section{RESULTADOS E DISCUSSÃO}

Este estudo com delineamento primordialmente descritivo, ao fotografar uma população definida em um determinado momento, demonstrou que a análise multivariada de correspondência múltipla pode ser aplicada para se conhecer alguns aspectos da relação homem-animal associados ao bem-estar do cão.

O caminho explorado para se chegar a análise multidimensional envolveu a caracterização do sistema de criação, a caracterização dos proprietários quanto à progressividade e atitude e a determinação de indicadores para a avaliação do bem-estar.
As frequências dos itens do sistema de criação encontrados foram: espaço disponibilizado para o desempenho das atividades do animal (96,7\% satisfatório); a liberdade (83,3\% viviam livres); a domiciliação (98,3\% não tinham acesso ao logradouro público); a higienização dos locais onde o animal dorme ( $95 \%$ satisfatória) e faz suas necessidades fisiológicas (95\% satisfatória); a imunização contra raiva $(98,3 \%)$ e outras doenças infecciosas $(65 \%)$; o controle de parasitos internos $(76,7 \%)$ e externo $(98,3 \%) ; 0$ tratamento respeitoso $(86,7 \%)$ e a efetiva participação dos proprietários nos momentos de interação através de brincadeiras (85\%) e passeios (46,7\%).

Dos 60 cães avaliados, exatamente $60 \%$ deles apresentavam 'condição corporal ideal', 21,6\% estavam com peso abaixo do ideal, $16,6 \%$, acima do peso e apenas $1,7 \%$ $(n=1)$ encontrava-se na condição de obeso (Quadro 1).

A maioria da amostra (83.3\%) era de animais mansos. Apenas 16,7\% foram considerados agressivos pelos proprietários e pela pesquisadora.

Noventa por cento dos cães foram considerados tranquilos por ocasião da observação realizada durante a entrevista.

$\mathrm{Na}$ representação gráfica de $\mathrm{P}_{k}$ contra $A_{k}$ a maioria dos índices ficou situada encima de um lado do eixo de " $y$ " imaginário. Isto significa que a maior parte dos proprietários foi classificada como progressista e com atitude positiva em relação ao bem-estar animal. Os conservadores foram poucos $(n=5)$ e não houve representação de um universo de atitude negativa (Figura 1).

As respostas relativas às atitudes positivas mostraram uma discrepância entre o posicionamento da maioria dos proprietários e o resultado obtido pela classe de variável 'bem-estar adequa- 
Quadro 1 - Graduação dos indicadores de bem-estar, da condição corporal segundo Laflame (1997) e caracterização do bem-estar de acordo com as graduações

\begin{tabular}{cccccccccccc}
\hline $\mathbf{N A}$ & $\mathbf{C C}$ & $\mathbf{I N}$ & $\mathbf{E T}$ & $\mathbf{L}$ & $\mathbf{B E}$ & $\mathbf{N A}$ & $\mathbf{C C}$ & $\mathbf{I N D}$ & $\mathbf{E T}$ & $\mathbf{L}$ & $\mathbf{B E}$ \\
\hline $\mathbf{1}$ & 0 & 0 & 0 & 5 & 1 & $\mathbf{3 1}$ & $\mathbf{0}$ & $\mathbf{0}$ & $\mathbf{0}$ & $\mathbf{5}$ & $\mathbf{1}$ \\
$\mathbf{2}$ & 0 & 3 & 0 & 4 & 0 & $\mathbf{3 2}$ & 0 & 0 & 0 & 4 & 1 \\
$\mathbf{3}$ & 1 & 0 & 0 & 3 & 0 & $\mathbf{3 3}$ & 0 & 2 & 0 & 4 & 0 \\
$\mathbf{4}$ & 1 & 0 & 0 & 6 & 0 & $\mathbf{3 4}$ & 1 & 0 & 0 & 3 & 0 \\
$\mathbf{5}$ & 0 & 3 & 0 & 4 & 0 & $\mathbf{3 5}$ & 1 & 0 & 0 & 3 & 0 \\
$\mathbf{6}$ & 1 & 0 & 0 & 3 & 0 & $\mathbf{3 6}$ & 0 & 1 & 0 & 4 & 0 \\
$\mathbf{7}$ & 0 & 0 & 0 & 4 & 1 & $\mathbf{3 7}$ & 0 & 3 & 0 & 5 & 0 \\
$\mathbf{8}$ & 0 & 0 & 0 & 4 & 1 & $\mathbf{3 8}$ & 0 & 0 & 0 & 4 & 1 \\
$\mathbf{9}$ & 1 & 1 & 0 & 6 & 0 & $\mathbf{3 9}$ & 0 & 0 & 0 & 4 & 1 \\
$\mathbf{1 0}$ & 0 & 0 & 0 & 5 & 1 & $\mathbf{4 0}$ & 0 & 0 & 0 & 5 & 1 \\
$\mathbf{1 1}$ & 2 & 0 & 0 & 7 & 0 & $\mathbf{4 1}$ & 0 & 0 & 3 & 5 & 0 \\
$\mathbf{1 2}$ & 1 & 0 & 0 & 6 & 0 & $\mathbf{4 2}$ & 0 & 0 & 1 & 5 & 0 \\
$\mathbf{1 3}$ & 0 & 0 & 0 & 5 & 1 & $\mathbf{4 3}$ & 1 & 0 & 0 & 6 & 0 \\
$\mathbf{1 4}$ & 1 & 0 & 0 & 3 & 0 & $\mathbf{4 4}$ & 1 & 0 & 0 & 3 & 0 \\
$\mathbf{1 5}$ & 0 & 0 & 0 & 4 & 1 & $\mathbf{4 5}$ & 0 & 0 & 0 & 5 & 1 \\
$\mathbf{1 6}$ & 0 & 0 & 0 & 5 & 1 & $\mathbf{4 6}$ & 0 & 0 & 0 & 4 & 1 \\
$\mathbf{1 7}$ & 1 & 2 & 2 & 3 & 0 & $\mathbf{4 7}$ & 0 & 0 & 0 & 5 & 1 \\
$\mathbf{1 8}$ & 0 & 0 & 3 & 4 & 0 & $\mathbf{4 8}$ & 0 & 0 & 0 & 5 & 1 \\
$\mathbf{1 9}$ & 0 & 0 & 0 & 5 & 1 & $\mathbf{4 9}$ & 0 & 0 & 0 & 5 & 1 \\
$\mathbf{2 0}$ & 0 & 0 & 0 & 4 & 1 & $\mathbf{5 0}$ & 1 & 0 & 0 & 6 & 0 \\
$\mathbf{2 1}$ & 1 & 0 & 0 & 3 & 0 & $\mathbf{5 1}$ & 1 & 0 & 0 & 3 & 0 \\
$\mathbf{2 2}$ & 2 & 0 & 0 & 7 & 0 & $\mathbf{5 2}$ & 1 & 0 & 0 & 3 & 0 \\
$\mathbf{2 3}$ & 0 & 0 & 0 & 4 & 1 & $\mathbf{5 3}$ & 0 & 0 & 0 & 5 & 1 \\
$\mathbf{2 4}$ & 0 & 0 & 0 & 4 & 1 & $\mathbf{5 4}$ & 1 & 0 & 0 & 3 & 0 \\
$\mathbf{2 5}$ & 0 & 2 & 3 & 4 & 0 & $\mathbf{5 5}$ & 0 & 0 & 0 & 4 & 1 \\
$\mathbf{2 6}$ & 3 & 3 & 0 & 8 & 0 & $\mathbf{5 6}$ & 3 & 0 & 0 & 8 & 0 \\
$\mathbf{2 7}$ & 0 & 0 & 0 & 5 & 1 & $\mathbf{5 7}$ & 2 & 0 & 0 & 7 & 0 \\
$\mathbf{2 8}$ & 0 & 0 & 1 & 5 & 0 & $\mathbf{5 8}$ & 0 & 0 & 0 & 4 & 1 \\
$\mathbf{2 9}$ & 0 & 0 & 0 & 5 & 1 & $\mathbf{5 9}$ & 1 & 0 & 0 & 3 & 0 \\
$\mathbf{3 0}$ & $\mathbf{1}$ & $\mathbf{3}$ & $\mathbf{0}$ & $\mathbf{3}$ & $\mathbf{0}$ & $\mathbf{6 0}$ & $\mathbf{1}$ & $\mathbf{0}$ & $\mathbf{0}$ & $\mathbf{6}$ & $\mathbf{0}$ \\
\hline $\mathbf{N A}-\mathbf{N}$ & 0 & 0 & & 0 & - & 0 & 0 & 0 & 0 &
\end{tabular}

NA - Número do animal; CC - Condição corporal (0- ideal / 1,2 e 3- inapropriada); IND - Índole (0- manso / 1,2 e 3- bravo); ET - Estado de tranqüilidade (0- tranquilo / 1,2 e 3-intranquilo); L - Graduação segundo Laflame (1,2 e 3- subalimentado / 4 e 5- condição corporal ideal / 6,7,8 e 9- sobrealimentado); BE - Bem-estar (1- adequado / 0pobre)

do'. Exatamente $98,3 \%$ dos proprietários concordaram que promover 0 bem-estar animal significa também se preocupar com a sua saúde física e mental, no entanto, somente $43,3 \%$ dos cães experimentavam o bem-estar. Como pode ser visto na Figura 1, não há nenhuma representação de atitude negativa e apenas $8,3 \%$ dos proprietários foram caracterizados como conservadores. Assim, de acordo com este ensaio, pode-se afirmar que as atitudes e a progressividade dos proprietários, por si só, não são fatores determinantes para a promoção do bem-estar animal. A hipótese foi rejeitada.
A 'índole', o 'estado de tranquilidade' e a 'avaliação corporal' foram os três indicadores utilizados para a medição do bem-estar animal. $O$ animal 'manso', 'tranquilo' que apresentava uma 'avaliação corporal' ideal foi considerado desfrutar do bemestar adequado. Exatamente 83,3\% dos cães investigados eram 'mansos', $90 \%$ eram 'tranquilos' e $56,6 \%$ apresentavam uma boa 'condição corporal'. Entretanto, apenas $43,3 \%$ da população canina experimentavam bem-estar adequado por ocasião da entrevista. Em outras palavras, menos da metade dos cães estudados era 
simultaneamente, 'mansa', 'tranquila' e apresentava 'condição corporal ideal.

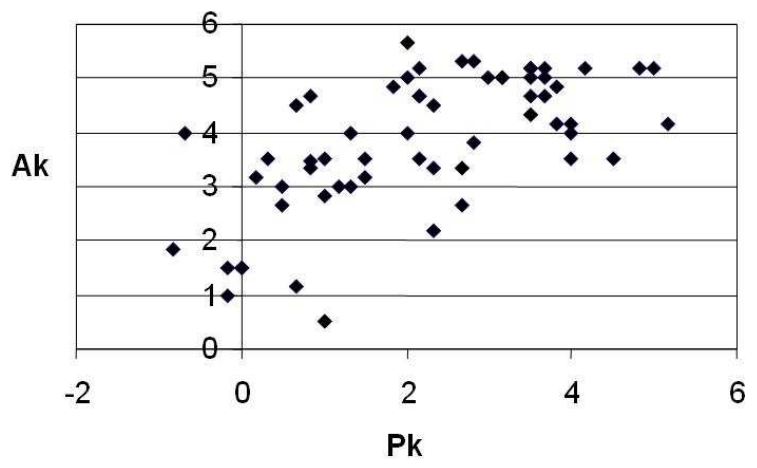

Figura 1 - Representação gráfica dos proprietários de cães segundo as coordenadas de atitude e progressividade

$\mathrm{Na}$ representação gráfica da análise multivariada de correspondência múltipla, as variáveis estão associadas de forma tridimensional - valores positivos acima e negativo abaixo (Figura 2). A intensidade das associações pode ser observada pela distancia euclidiana clássica do sistema algébrico, ou seja, pela distância das posições das variáveis nos quadrantes, onde a proximidade entre variáveis aponta o nível de associação. Duas variáveis no mesmo quadrante (diédro) estão associadas quanto mais próximas elas estiverem. Por conseguinte, quanto mais distante uma das outras mais fraca é a associação.

Não foi possível incluir todas as variáveis do estudo nesta análise porque algumas variáveis não apresentaram dispersão representativa. Entretanto, os resultados que se depreendem da representação gráfica, possibilitam a compreensão de associações entre as variáveis que representam fatores concorrentes para o bem-estar animal.

Os resultados obtidos com a análise multivariada de correspondência múltipla não estão sob a forma de correlação entre variáveis e, portanto, não são apropriados para demonstrar conexão causal. No entanto, foi possível, através das associações constituídas entre as variáveis, estabelecer conjeturas plausíveis.

A análise multidimensional revelou que nenhuma categoria de progressividade e atitude positiva está associada de modo satisfatório ao bemestar adequado.

Entre as três classes de renda $(A$, $B$ e $C)$, a classe de renda $A$ está mais associada ao bem-estar adequado.

As classes de variáveis 'intranquilidade' e 'a condição corporal inapropriada' apresentaram no plano tridimensional fortíssima associação com o bem-estar pobre. Enquanto as classes 'tranquilidade' e 'condição corporal apropriada' não apresentaram associação satisfatória com bem-estar adequado. A agressividade apresentou fraca associação com as demais classes de variáveis analisadas. Portanto, dentre os três indicadores empregados, o 'estado de tranquilidade' e 'a condição corporal' mostraram ser indicadores mais apropriados para medir o bem-estar pobre que o bemestar adequado. Diante do exposto deduz-se que o 'estado de tranquilidade' e a 'condição corporal' podem ser empregados como indicadores para avaliar o bem-estar do cão.

Os cães que experimentam bemestar pobre podem ser indiferentemente 'mansos' ou 'bravos'. Quando o cão é 'agressivo' os integrantes da família comumente 'não brincam', mas podem 'passear' com o animal. Os proprietários geralmente moram em 'apartamento', têm o cão como 'animal exclusivo' e permitem que ele 'entre' e 'durma no interior da residência'.

A classe de variável 'bem-estar adequado' apresentou-se mais associada à 'condição corporal ideal', seguida das classes 'mansidão', 'brincar' e 'tranquilidade'. Os proprietários de cães que experimentam 'bem-estar adequado' possuem 'outro animal de estimação', geralmente 'não 


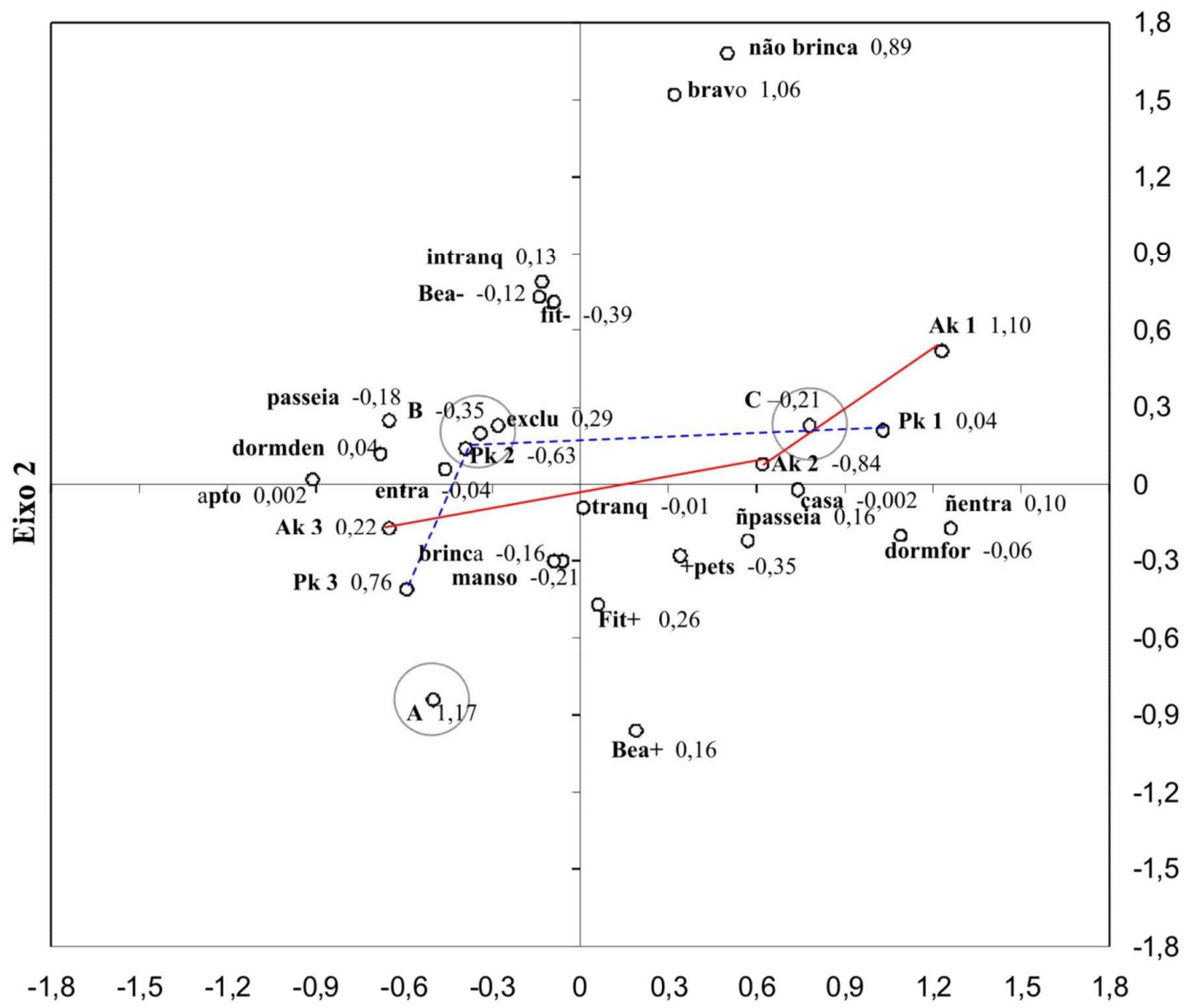

Eixo 1

Figura 2 - representação gráfica das variáveis selecionadas, segundo os eixos 1 e 2 na análise multivariada de correspondência múltipla. Inércia do sistema algébrico tridimensional é de $62 \%$. O sentido e o valor das coordenadas no terceiro eixo estão apostos à identificação das variáveis: Bea+ (bem estar positivo), Bea - (bem estar negativo), Fit - (condição corporal inapropriada), Fit + (condição corporal ideal), bravo, manso, intranq (intranquilo), tranq (tranquilo), brinca, não brinca, ñpasseia (não passeia), passeia, entra, ñentra (não entra), dormden (dorme dentro), dormfor (dorme fora), apto (apartamento), casa, +pet (outros animais de estimação), exclu (cão como animal exclusivo), A, B e C (classes de renda familiar), $A_{k} 1$, $A_{k} 2$ e $A_{k} 3$ (classes de atitude positiva), $P_{k} 1, P_{k} 2$ e $P_{k} 3$ (classes de progressividade).

passeiam' com o animal, podem ou não permitir que ele 'entre no interior da residência' e 'durma no interior da residência'.

Entre todas as classes de variáveis estudadas, 'mansidão' e 'brincar' apresentaram maior associação entre si. A notável associação das classes 'manso' e 'brincar' tem um sentido ambíguo: os animais brincam porque são mansos (fator hereditário) ou o fato de interagir através de brincadeiras com os seus familiares (fator ambiental) desde o período de socialização tornou esses animais mansos? Este estudo não permite explicar essa ambiguidade, mas sinaliza mostrando claramente que o cão agressivo não brinca com seus familiares.

A localização da classe de variável 'tranquilo' no plano tridimensional mostra-se quase equidistantes do 'bemestar pobre' e 'bem-estar adequado'. O cão 'tranqüilo' pode experimentar tanto 'bem-estar adequado' como 'bem-estar pobre'. Segundo este resultado, o 'estado de tranquilidade' não atesta o 'bem-estar adequado'. Um animal aparentemente tranquilo pode não estar experimentando bem-estar. 
Comumente, o proprietário que brinca com o seu cão 'não passeia' com ele, deixa-o 'entrar' e 'dormir no interior da residência', pode ou não conviver com outros 'animais de estimação', morar em 'casa' ou 'apartamento'. Um cão 'manso' que 'brinca' rotineiramente, geralmente é 'tranquilo'. Sua 'condição corporal' pode ser satisfatória e o seu 'bem-estar ser adequado'.

Um cão 'intranquilo' pode 'brincar' ou 'não brincar' com os integrantes da família. A brincadeira pode favorecer a manutenção do estado de tranquilidade, da 'condição corporal ideal' e o 'bemestar adequado', no entanto, pode não evitar, que o animal seja intranquilo, apresente 'condição corporal inapropriada' e experimente 'bem-estar pobre'.

Embora a classe de variável 'brincar' tenha se apresentado bastante associada à 'tranquilidade' e constituir um fator importante para 0 estabelecimento de interação mais íntima e prazerosa entre o proprietário e o cão, 'brincar' é apenas um fator contribuinte para 0 'estado de tranquilidade', devendo haver outros fatores de caráter emocional concorrentes tanto para 0 estado de 'tranquilidade' como para o estado de 'intranquilidade'.

Neste estudo, apesar de $85 \%$ dos proprietários garantirem o compromisso de brincar com seus cães e a variável 'brincar' se mostrar satisfatoriamente associada ao 'bem-estar adequado', a maioria dos proprietários não conseguiram proporcionar bem-estar adequado aos seus animais. Este resultado é corroborado com a opinião de Baxter (1988, p.347) ao assinalar que o desempenho comportamental não é o único meio de satisfazer necessidades de bem-estar.

O bem-estar tem implicações cognitivas, se um animal não estiver atento ou antecipando um fato, a não realização do evento não afetará necessariamente 0 seu bem-estar (Hughes, 1988). Neste caso, para alguns animais é muito importante passear e brincar, mas não para outros. O passeio e a brincadeira podem não estar envolvidos com o processo de cognição, e consequentemente, não se caracterizar como uma necessidade. Broom (1998) enfatiza que o sentimento - componente das emoções relacionadas ao processo cognitivo pode mudar o comportamento imediatamente ou eventualmente, mas necessidade não atua desse modo. O não atendimento das necessidades está frequentemente, mas nem sempre, associado aos sentimentos que prejudicam o animal, enquanto sentimentos desenvolvidos pelo animal que favorecem 0 bem-estar estão associados à satisfação das necessidades (Broom e Fraser, 2007).

Se a privação de brincadeiras e passeios não causa sofrimento a um determinado animal, brincar e passear para esse animal não se constitui uma necessidade. Neste caso específico, o passeio e a brincadeira não estão envolvidos com o processo de cognição e, por conseguinte com o sentimento. Quando brincar e passear não são percebidos como necessidade, não promovem de modo direto a elaboração de sentimentos e, conseguintemente, não são fatores que influenciam obrigatoriamente ao bem-estar dos cães. No entanto, com os resultados obtidos não é possível saber se os níveis de motivação de alguns cães, responsável pela possível indiferença à brincadeira ou ao passeio, dependem exclusivamente das características internas peculiares ao indivíduo, ou se estas características foram moldadas por influências do meio ambiente.

Outros resultados estão em desacordo com alguns aspectos da relação homem-animal considerados objetos de crenças sustentadas pelo senso comum. A análise mostrou que 
morar em casa não é uma circunstância sine qua non para o favorecimento do bem-estar adequado, e também, morar em apartamento não é um fator determinante para a ocorrência de bemestar pobre. Igualmente, o cão manso e tranquilo, que brinca rotineiramente e vive no interior da residência, não experimenta necessariamente bemestar adequado. $O$ animal que entra e dorme no interior da residência tem mais possibilidade de experimentar bem-estar pobre que bem-estar adequado. É provável que a maior proximidade do cão com os familiares, se constitua em um fator psicossocial desfavorável para a promoção do bemestar.

Os proprietários que vivem em apartamento tentam compensar 0 pequeno espaço proporcionando passeios diários ao seu cão. Contudo, ao contrário que muitas pessoas pensam o passeio por si só, não mostrou ser uma contribuição satisfatória para o estabelecimento da tranquilidade e mansidão, e tampouco, para manter a condição corporal ideal e o bem-estar do cão. O cão que passeia pode ser obeso e 'intranquilo'. O cão que não passeia pode apresentar condição corporal ideal, ser tranquilo e manso.

É notória a importância do passeio como um fator concorrente para a manutenção da condição corporal, no entanto, assim como a nutrição e o exercício são importantes para a saúde do cão, o fator emocional também deve ser reputado como algo fundamental para o bem-estar desta espécie. Esta consideração apóia-se não somente nos autores Dawkins (1990), Duncan (1996) e Broom (1998), mas também na forte associação obtida entre as classes brincar e condição corporal ideal.

Embora 0 tipo de análise empregada não permita explorar correlações, as associações evidentes entre possuir 'outro animal de estimação' e o animal ser 'manso', 'tranqüilo' e apresentar 'condição corporal ideal' colaboram para estabelecer relação entre 'bem-estar adequado' e a existência de 'outro animal de estimação'. Este resultado valida uma crença sustentada pelo senso comum: os animais parecem ficar mais calmos e vivazes quando tem outro animal como companheiro ou vivendo na mesma casa. A análise comprovou que o 'bemestar adequado' do cão está mais associado a 'outros animais de estimação' que a condição de cão 'exclusivo'. Provavelmente, um proprietário que tem mais de um animal de estimação, preocupa-se em enriquecer a vida de seu cão com um companheiro, ou simplesmente, gosta de interagir e desfrutar ativamente da companhia de vários animais. A relação simultânea com os animais talvez evite o apego exagerado com o seu cão e problemas subsequentes prejudiciais para o estabelecimento do bem-estar.

As frequências dos itens referentes ao sistema de criação demonstraram que a maioria dos proprietários cuida bem de seus cães e brinca com o seu animal. Somente a frequência relativa ao item passeio mostra-se abaixo de cinquenta por cento. Também, a maior parte dos proprietários foi classificada como progressista e com atitude positiva em relação ao bem-estar animal. No entanto, menos da metade dos cães $(43,3 \%)$ experimentavam bem-estar adequado por ocasião da pesquisa. Deste modo, pode-se inferir que a progressividade, a atitude positiva e o comprometimento do proprietário com os cuidados necessários para proporcionar uma boa qualidade de vida ao cão, não são suficientes para favorecer o bem-estar da maioria dos animais. Estes animais devido às circunstâncias ou as condições estabelecidas para sua convivência no âmbito familiar não conseguiram 
adaptar-se ao ambiente onde vivem. A partir desta inferência e da frequência de animais que experimentavam bemestar pobre $(56,6 \%)$, entende-se que possivelmente, a relação da maioria dos proprietários com os cães estudados não era satisfatória.

Neste estudo não foi observada associação entre o desempenho da maioria dos proprietários e a conquista do bem-estar adequado. Isto demonstra que em algumas ocasiões, o sistema de controle do animal em relação às adversidades decorrentes do ambiente psicossocial, pode não ser eficiente o bastante para garantir a sua estabilidade mental e corporal. Provavelmente, o bem-estar está relacionado também a outros fatores de natureza subjetiva inerente à interação interespécie.

Futuros estudos deverão comprometer-se em revelar conexões de alguns aspectos do ambiente psicossocial e o bem-estar do cão.

\section{CONCLUSÃO}

As atitudes positivas, a progressividade dos proprietários e as boas condições de criação não são fatores determinantes para a promoção do bem-estar animal e, ao mesmo tempo, permite afiançar que o ser humano está testemunhando o começo de uma tendência ética favorável para a relação homem-animal. A qualidade dessa relação ainda é insatisfatória para muitos cães que vivem provavelmente em condições comprometedoras para o seu bem-estar.

\section{NOTA INFORMATIVA}

Esta pesquisa foi submetida à avaliação e aprovada pelo Comitê de Ética em Pesquisa - Parecer no. ETIC 545/06/06 e pelo Comitê de Ética em Experimentação Animal - Protocolo 175/2006.

\section{REFERÊNCIAS}

BAXTER, M.R. Needs Behavioural or Psychological? Applied Animal Behaviour Science, v. 19, p. 345-347, 1988.

BEKOFF, M. Encyclopedia of animal rights and animal welfare. Connecticut: Greemwood Press, 1998. 472 p.

BROOM, D.M. Indicators of poor welfare. British Veterinary Journal, v.142, p.524-525, 1986.

BROOM, D.M. Animal welfare: concepts and measurement. Journal Animal Science, v.69, p.4167-4175, 1991.

BROOM, D.M. Welfare, Stress, and the Evolution of Feelings. Advances in the Study of Behavior, v.27, p.371-403, 1998.

BROOM, D.M.; FRASER, A.F. Domestic Animal Behaviour and Welfare. 4. ed. Oxfordshire: CABI International, 2007. 438 p.

CLARK, J.D.; RAGER, D.R.; CALPIN, J.P. Animal well-being I. General considerations. Laboratory Animal Science, 47, 564-570, 1997a.

CLARK, J.D.; RAGER, D.R.; CALPIN, J.P. Animal well-being III. An overview of assessment. Laboratory Animal Science, v. 47, p. 580-585, 1997b.

DAWKINS, M.S. From an animal's point of view: Motivation, fitness, and animal welfare.

Behavioral and Brain Science, v. 13, p. 1-61, 1990.

DUNCAN I.J.H. Animal rights-animal welfare: a scientist's assessment. Poultry Science, v. 60, p. 489-499, 1981.

DUNCAN, I.J.H. Animal welfare defined in terms of feelings. Acta Agricultarae Scandinavica Supplementum, v.27, p. 29-35, 1996.

GUILHERMINO, M.; SAMPAIO, I.B.M. An approach to the characterization of english and welshdairy farmers as to progressiveness and attitude toward Computerized Information Systems. Archivo Latinoamericano de Produccion Animal , v.7, p. 53-61, 1999.

HOFER, H.; EAST, M.L. Biological Conservation and Stress. Advances in the Study of Behavior, v.27, p. 405-426, 1998.

HUGHES, B.O. Discussion 2. In: Proceedings from workshop on behavioural needs. Applied Animal Behaviour Science, v.19, p. 356-367, 1988.

JAGOE, A.; SERPELL, J. Owner characteristics and interactions and the prevalence of canine 
behaviour problems. Applied Animal

Behaviour Science, v. 47, p. 31-42, 1996.

KANDEL, E.R.; SCHWARTZ, J.H.; JESSELL, T.M. Fundamentos da neurociência e do comportamento. Rio de Janeiro: Prentice-Hall, 1997. 591p.

LAFLAMME, D.P. Development and validation of a body condition score system for dogs. Canine Practice, v.22, p.10-15, 1997.
MÜLLER, D. C. de M. Adaptação do índice de massa corporal Humano para cães. 2007. Santa Maria, 32 p. Dissertação (Mestrado em Medicina Veterinária) - Curso de Pós-graduação em Medicina Veterinária, Universidade Federal de Santa Maria.

ZIMBARDO, P.G.; EBBERSEN, E.B. Técnicas para mensuração de atitudes. In: Influencia em Atitudes e Modificação de Comportamento. São Paulo: Edusp, 1973. Apêndice A, p.125. 